\title{
Avaliando aprendizagem em simulações empresariais
}

\author{
Ângela Versiani *
}

Roberto C. Fachin**

\section{Resumo}

Este artigo aborda o tema da aprendizagem gerencial, a partir da ótica da utilização das metodologias de simulações empresariais capazes de incentivar a formação de identidades profissionais calcadas na capacidade de autoquestionamento e desenvolvimento do pensamento sistêmico. Parte do pressuposto de que as atividades educacionais e de treinamento são fontes ativas pa ra a formação de agentes de aprendizado organizacional e 0 estabelecimento de metodologias específicas com impactos diferenciados em relação a esses objetivos. A fim de subsidiar essa discussão, 0 artigo apresenta os resultados de uma pesquisa exploratória com estudantes de pós-graduação que utilizaram jogos de empresa em sua formação profissional. De forma geral, a conclusão é a de que as simulações são metodologias capazes de estimular mais a aprendizagem de elo duplo e, menos, a aprendizagem de nível instrumental.

Palavras-chave: simulações; jogos de empresa; aprendizagem gerencial.

\begin{abstract}
This is a paper that focuses on managerial learning as looked from the viewpoint of simulation games as a method that could be helpful to form professional identities capable of self-questioning and of development of a systemic thinking. Its basic premise is that educational as well as training activities are active sources for the development of agents of organizational learning and that methodologies have distinctive impacts on attainment of such objectives. So that this discussion could began, the article presents an exploratory research with graduate students who have participated in simulation games during their educational preparation. In general terms, one concludes that simulations are methods capable of fostering double loop learning but not so much learning of instrumental objetives.
\end{abstract}

Key words: simulations; simulation games; managerial learning.

\section{Introdução}

No campo educacional, os jogos de empresas são utilizados como resposta aos desafios do desenvolvimento das habilidades de raciocínio e sua integração com as dimensões comportamentais e afetivas. Sua superioridade em relação a outros métodos de ensino tem sido sugerida, uma vez que iniciam o aluno no universo da aprendizagem vivencial.

Segundo Sauaia (2000), os jogos empresariais propiciam "o desenvolvimento de habilidades de gestão expressas pelas variáveis 'praticar a tomada de decisões', 'praticar a análise de problemas' e 'praticar o controle dos resultados", coadunando-se com as propostas recentes de educação gerencial propagadas pelas abordagens da aprendizagem organizacional. A perspectiva gerencial dessas abordagens (DI BELLA; NEVIS,1998; ELKJAER, 2001considera que as principais barreiras para a mudança das organizações referem-se à

\footnotetext{
* Doutoranda em administração pela FEA/USP. Professora da PUC-Minas. Endereço: Pontificia Universidade Católica de Minas Gerais - Programa de Pós-graduação em Administração - Av. Itaú7, 525 - Prédio Redentoristas - Bairro Dom Bosco - CEP 30730- 280 - Belo Horizonte, Minas Gerais. E - mail: versiani@ pucminas.br.

* Professor da PUC-Minas / Fundação Dom Cabral. Doutor em Ciências Humanas e Livre Docente em Política e Administração. Endereço: Pontifícia Universidade Católica de Minas Gerais - Programa de Pós-graduação em Administração - Av. Itaú7, 525 - Prédio Redentoristas - Bairro Dom Bosco - CEP 30730- 280 - Belo Horizonte, Minas Gerais. E - mail: rcfachin@ portoweb.com.br.
}

* Artigo recebido em outubro de 2006 e aceito para publicação em novembro de 2006. 
capacidade limitada dos indivíduos, tanto no plano de sua racionalidade como no de suas habilidades, conhecimentos e visões de mundo (ALEE,1997; ARGYRIS; SCHÖN,1978; SENGE, 1990). Decorrem daí os argumentos em prol da necessidade de se desenvolver a habilidade para aprender dos gestores, pois indivíduos são considerados os principais agentes do aprendizado organizacional. Afinal, são eles que em todos os níveis se deparam com novas idéias, erros e outras oportunidades.

Quando as pessoas escolhem agir com essas descobertas e trazê-las à atenção das organizações, assumem o papel de agentes de aprendizagem. Geralmente, esse papel implica riscos e requer um conjunto particular de atributos, tais como o pensamento sistêmico, o questionamento da visão que se tem dos negócios e a capacidade de trabalhar em grupo (ARGYRIS; SCHÖN,1978; SENGE, 1990;FRIEDMAN,2002).

Tem sido aceito que a utilização dos jogos de empresa proporciona aos participantes maior satisfação do que outros métodos de ensino, envolvendo-os com o processo de aprendizagem (SAUAIA, 2000). Entretanto, os significados que emergem para eles de sua vivência no jogo, contribuindo para a construção de sua identidade profissional, ainda parece ser uma lacuna na literatura. Os estudos sobre simulação ainda não aprofundaram questões referentes à aquisição, integração e atualização dos conhecimentos gerenciais propiciados pelos jogos. No caso específico de se utilizar as simulações como elementos propulsores da formação dos agentes do aprendizado organizacional, emerge a pergunta sobre a potencialidade dessa metodologia em estimular identidades profissionais capazes de exercitar o auto-questionamento e o desenvolvimento do pensamento sistêmico.

Levando em consideração essa questão, este artigo tem como principal contribuição levantar evidências que possam aprofundar as reflexões acerca da construção do conhecimento, a partir das simulações. O objetivo é discutir as potencialidades dos jogos de empresas como instrumentos de incentivo à formação de agentes do aprendizado organizacional. Considera-se que cogitações teóricas sobre ensino-aprendizagem e aprendizagem organizacional deveriam estar na raiz da avaliação de resultados de aprendizagem em simulações empresariais.

\section{Elementos da identidade dos agentes do aprendizado organizacional}

O campo da aprendizagem organizacional vem se consolidando nas ciências gerenciais (CHILD,1997 DOGSON,1993; DI BELLA; NEVIS,1998; SMITH,1997) com os gestores sendo chamados a desenvolver competências, evitar erros de outrora, tanto quanto antecipar-se a futuros problemas. Shrivastava (1983) afirma que o aprendizado organizacional é resultado das interações que geram adaptação individual aos subgrupos funcionais, que por sua vez se ajustam ao nível da corporação. Nesse sentido, o aprendizado organizacional realiza-se quando os indivíduos explicitam seus modelos mentais e, interagindo, modificam-nos mutuamente para criar modelos mentais organizacionais compartilhados.

Alguns autores, como Garvin (1993), Nonaka e Takeuchi (1995) e Senge (1990), entre outros, enfatizam claramente o papel do indivíduo nos processos de aprendizado organizacional, postulando dimensões cognitivas, de habilidades e atitudes e comportamentais que devem ser desenvolvidas para que as pessoas sejam agentes eficazes de aprendizagem. Por exemplo, para Garvin (1993), o primeiro estágio é o cognitivo Nesse estágio, os membros da organização devem ser expostos a novas idéias, expandirem seus conhecimentos e começarem a pensar de modo diferente. O segundo é atitudinal, quando novos valores e normas são internalizados, e, por fim, o terceiro estágio, que se refere às mudanças de comportamento, as quais conduzem a melhorias no resultado da empresa. Já Nonaka e Takeuchi (1995) incluem altos padrões intelectuais, senso de compromisso para criar o mundo com perspectiva própria, grande variedade de experiências tanto dentro quanto fora das organizações, habilidade de comunicação e abertura para debates.

Senge (1990) é contundente ao afirmar que as deficiências de aprendizagem das organizações ocorrem porque os indivíduos agem segundo rígidos modelos mentais, bem como evitam debates e divergências. Ressalta-se que quando há polarização de opiniões, a tendência é procurarem culpados, esquivando-se de uma autoreflexão crítica que possa apontar como a própria pessoa contribuiu para alguma falha. 
Compartilhando a idéia de que os indivíduos são limitados no plano da sua racionalidade, de suas habilidades, dos seus conhecimentos e visão de mundo, Argyris e Schön (1978) também destacam que a capacidade de aprender das organizações está em desenvolver esquemas conceituais que capacitem os indivíduos a perceberem que seus atos levam a consequiências de longo prazo. Para isso, têm de libertar-se de seu próprio raciocínio, desencadeando 1978.

Portanto, a capacidade de aprender das organizações está em desenvolver esquemas conceituais que capacitem os indivíduos a ver que seus atos produzem consequências de longo prazo. As maneiras de pensar tradicionais devem ser superadas, fazendo aflorar modelos mentais abertos para o inusitado, valorizando a auto-reflexão, para que assim seja possível entender os padrões sutis que regem o comportamento das pessoas. Os indivíduos devem indagar sobre o próprio comportamento, construir o pensamento sistêmico e buscar ações que produzam significativas melhorias organizacionais.

Friedman (2002) define esse tipo de reflexividade a partir das seguintes perguntas: O que eu fiz para contribuir para essa situação? O que deveria fazer para contribuir para sua solução? Isso significa descobrir a responsabilidade pelas causas de resultados não desejados e estratégias ou alternativas para tentar corrigi-los.

Quando a questão é aumentar a capacidade de aprendizado organizacional, as teorias de desenvolvimento de recursos humanos postulam que os programas de educação são pilares que auxiliam os indivíduos na descoberta e desenvolvimento de suas potencialidades. Os educadores de adultos acreditam que o aprendizado é basicamente um empreendimento que se inicia no indivíduo, através da ampliação de sua base de conhecimentos, conduzindo-o à descoberta e construção de suas competências e habilidades. Os profissionais da educação, através de várias metodologias, buscam não só despertar o aprimoramento profissional como desencadear o compromisso dos indivíduos com o seu próprio processo de aprender. Trata-se da conscientização de suas limitações, de seus afetos e de suas potencialidades como pessoas que de modo proativo podem definir e delimitar o seu espaço vital.

Uma concepção pragmática de aprendizagem que busca, através de programas educacionais, interligar experiências individuais e coletivas com a reflexão sobre essas mesmas experiências pode ser encontrada nas simulações ou jogos de empresa que parecem contribuir para que os indivíduos questionem a forma como raciocinam, como se relacionam e assim questionem sua concepção a respeito dos negócios.

\section{0 aprendizado gerencial com simulações empresariais}

Utilizadas desde a década de 1950 (SAUAIA, 1990), as simulações empresariais têm despertado a curiosidade de pesquisadores e educadores quanto à validade de sua utilização e suas consequências sobre o aprendizado. Efetivamente, buscando reunir profissionais interessados na temática das simulações e aprendizado, foi criada, em 1974, a Association for Business Simulation and Experiential Learning (Absel). Desde então, estudiosos passaram a avaliar tais recursos de aprendizagem quer como pedagogia isolada, quer em base comparativa com outras pedagogias, tais como conferências, aulas expositivas e casos de ensino.

Faria (2000), em revisão da história da Absel, categorizou a pesquisa produzida em duas grandes áreas de interesse. Na primeira, aparecem estudos que buscaram predizer o desempenho nos jogos a partir da consideração das características dos participantes. Chegou-se à conclusão de que os estilos democráticos estavam associados a resultados de maior êxito, e de que personalidades mais racionais ou analíticas tinham melhor desempenho do que as de caráter mais sensitivo ou emocional. Na segunda área, os estudos comparam os jogos de empresa com outras metodologias de ensino. Por exemplo, em relação ao aprendizado do gerenciamento estratégico, os jogos por computador foram considerados mais eficazes do que os casos de ensino.

A avaliação das simulações pelo público que as utilizou em cursos de desenvolvimento gerencial indicam ampla aceitação dessa metodologia. Além disso, estudantes declararam preferir jogos e simulações como o tipo de aula que lhes propiciava aprendizagem com maior satisfação e envolvimento (PEACH; HORNYAK, 2003; 
SAUAIA, 1990). Essa preferência parece estar relacionada com a dimensão afetivo-emocional desencadeada pelo jogo, colocando o participante como elemento ativo de um processo de educação que é vivencial.

A aprendizagem vivencial é delineada em ciclos, onde as etapas passam de uma fase de experiência concreta, (deobservação e reflexão) até a formação de conceitos e generalizações com posterior teste ou a chamada experimentação ativa (KOLB,1976). Nas simulações com computador, os estudantes, além da experiência concreta na forma de resultados econômico-financeiros, também refletem sobre esses resultados ("observação e reflexão"). Feita a avaliação de seu significado, eles o relacionam com seu conhecimento prévio, interpretam o ambiente mercadológico ("formação de conceitos e generalizações") e, finalmente, tomam. um novo conjunto de decisões ("experimentação ativa") (DEVITT, 1997). Essa dinâmica sugere que cada pessoa no ato do jogo faz inferências sobre a validade de suas ações, desenvolve conceitos, bem como traz à tona concepções que são confirmadas ou desfeitas, colocando em evidência a importância de se estabelecer metas de aprendizagem.

O fato é que as metas de aprendizagem têm sido um tópico constante de discussão entre os que elaboram as simulações (developers) e os usuários. Jogos de empresas parecem satisfazer a uma ampla gama de objetivos. Um exemplo é o apresentado por Gosen e Washbush (1999), quando identificam uma lista extensiva de 40 objetivos. Porém, apesar da amplitude de propósitos da utilização dos jogos ou simulações, estes podem ser classificados em três grandes categorias: aquisição de conhecimentos, desenvolvimento de atitudes e desenvolvimento de habilidades (SAUAIA,2000; SCHUMANN et al, 2001). Podem ser utilizados tanto por quem tenha conhecimentos prévios da área de Administração quanto por quem está sendo iniciado no campo (SAUAIA,2000).

Tendo em vista que os jogos servem a vários objetivos, a implicação óbvia é que o conteúdo ensinado varia em função desses objetivos. Os principais conteúdos descritos, desde 1975, incluem habilidades empreendedoras, modelos matemáticos, conceitos básicos de finanças, habilidades interpessoais, resolução de conflitos e habilidades de comportamento grupal, dentre outras (FARIA, 2000). Assim, tanto conteúdos cognitivos quanto conteúdos comportamentais e afetivos têm sido abordados. Isso faz supor que os jogos de empresa despertam os indivíduos para os níveis de aprendizado instrumentais (single loop ou elo único), cujas soluções são estritamente racionais, e para a aprendizagem considerada de elo duplo (ou double loop). (ARGYRIS; SCHÖN, 1978). Nesta, as imagens e o entendimento dos problemas são modificados, reestruturando ou atribuindo novos significados a suas ações.

Um terceiro nível de aprendizagem que os jogos poderiam suscitar é denominada deutero (ARGYRIS; SCHÖN, 1978), com os participantes levantando questões sobre o aprendizado em si.

Não se deve deixar de mencionar a complexidade educacional das simulações, principalmente, devido às estruturas programáticas de ensino e a interferências outras no processo educacional, como o ambiente do treinamento, o perfil dos participantes, a formação das equipes e a complexidade dos jogos. Nesse sentido, a eficiência educacional é resultante tanto do ambiente simulado, como de fatores exógenos a eles (SAUAIA, 2000).

A complexidade que permeia o aprendizado em jogos e simulações acaba por favorecer a natureza não conclusiva dos estudos, limitando o alcance das generalizações. Conforme Peach e Hornyak (2003), há amplo desacordo quanto à associação entre simulação e aprendizado, sendo questionados tanto a simulação quanto o aprendizado como construtos que possam ser mensurados (ANDERSON; LAWTON,1997).

Apesar de não se estabelecer precisamente o tipo de relação que existe entre as simulações e o aprendizado devido aos problemas de medição, é aceito que existe algum relacionamento entre ambos (ANDERSON; LAWTON, 1997), fazendo com que o debate prossiga. A busca de precisão tem levado alguns autores a estabelecer distinções entre o aprendizado percebido e o aprendizado objetivo. No primeiro caso, refere-se àquilo que os participantes percebem como aprendido com as simulações, e na segunda abordagem configurase aquilo objetivamente aprendido, explicitado através de avaliações conceituais.

Visando abordar o relacionamento entre aprendizado percebido e aprendizado objetivo, Gosen e Washbush (1999) concluíram que não há relacionamento entre as percepções do aprendizado pelos indivíduos e as 
medidas objetivas. Isso significa que um indivíduo pode sentir que aprendeu, sem necessariamente ter incorporado um novo conhecimento conceitual. Resultados demonstram que indivíduos que obtiveram altos escores em medidas objetivas de aprendizado não perceberam que aprenderam mais do que aqueles que obtiveram escores menores. Constatou-se uma correlação negativa entre as medidas objetivas e o grau que os participantes pensam que aprenderam com os jogos. Por outro lado, os dados evidenciaram a presença de correlação positiva entre percepção de aprendizado e desempenho. Assim, no estudo desses autores, o aprendizado percebido não teve relação com as medidas objetivas, implicando que a declaração dos participantes sobre o que aprenderam e a medida objetiva desse aprendizado têm naturezas distintas, sendo a percepção de aprendizado e os índices objetivos diferentes fenômenos.

Tais diferenças conduzem ao seguinte raciocínio: primeiro, o aprendizado objetivo já é algo incorporado e não é sentido como componente que esteja moldando uma nova realidade vivida; segundo, o aprendizado percebido aparece como algo novo, ainda não introjetado plenamente. Perceber que algo mudou implica reconhecer a incorporação de novos elementos às narrativas individuais, sem necessariamente ter consciência de quais são esses elementos.

O fato é que não se pode descartar a importância da percepção do aprendizado, pois ao indicar a si mesmos que aprenderam algo, os indivíduos acionam os elementos que são dotados de importância para a constituição do seu self. O "self" decorre da experiência vivenciada pelo indivíduo, no qual ele é duplamente sujeito e objeto da ação. Nesse sentido, ele desencadeia um processo de auto-indicação influenciado pelo contexto no qual está inserido e pelas regras sociais que lhes são subjacentes (WEIGERT; TEITGE, 1990), contribuindo para a introjeção de determinados valores à definição de sua identidade profissional.

Reconhecendo que há várias possibilidades de aprendizado ao se utilizar simulações empresariais, dentre elas a possibilidade de se estimular a construção de identidades gerenciais pautadas pelas características dos agentes de aprendizado organizacional, este artigo procurou verificar se os jogos incitam os participantes a compreenderem suas ações a partir do ponto de vista sistêmico, desencadeando mudanças em sua concepção sobre o gerenciamento do negócio.

\section{A pesquisa da aprendizagem em situação de simulação empresarial}

Com o propósito de discutir a utilização dos jogos de empresas como metodologia adequada a programas educacionais cujos objetivos sejam incrementar as capacidades de aprendizado dos seus membros, foi feita uma pesquisa com 10 alunos que utilizaram jogos de empresa em seu curso de pós-graduação stricto sensu, no ano de 2003.

Quanto à descrição do jogo, cabe salientar que os 10 alunos foram divididos em equipes de duas pessoas, escolhidas aleatoriamente pelo professor. O jogo teve periodicidade semanal, sendo executadas oito rodadas de tomadas de decisão com duração total de três meses. Durante o curso foram utilizados dois simuladores diferentes. As atividades do programa foram as mesmas para os dois simuladores utilizados e estão descritas no quadro 1. Cabe destacar que não se procurou investigar os resultados de um tipo específico de jogo, mas sim a totalidade da vivência que expressa os seguintes objetivos específicos de pesquisa:

a) determinar o que os estudantes perceberam ter aprendido a partir de sua vivência com o jogo;

b) identificar os fatores que facilitaram o aprendizado;

c) identificar o papel do jogo a partir da vivência dos participantes;

d) identificar as dimensões do aprendizado que os participantes mais utilizaram;

e) verificar as imagens que os indivíduos desenvolveram da administração a partir dos jogos. 
Quadro 1 - Atividades do programa com jogos de empresas

\begin{tabular}{ll}
\hline Reuniões & Atividades \\
\hline \multirow{2}{*}{ Inicial } & Apresentação do programa vivencial \\
\cline { 2 - 2 } & Discussão do caso empresarial a ser jogado \\
\hline Tomada de decisão experimental - ensaio \\
\hline Intermediária & Formulação do Plano de Gestão Anual \\
\hline Final & Retrospectiva dos acontecimentos \\
\hline & Seminário de avaliação dos resultados \\
\hline
\end{tabular}

Fonte: elaborado pelos autores de acordo com as atividades desenvolvidas no programa de simulação empresarial.

Portanto, a pesquisa em questão teve natureza qualitativa e caráter descritivo, buscando captar os sistemas de significados presentes na utilização das simulações a partir da vivência dos participantes nesses jogos. Como instrumento na coleta de dados, recorreu-se a entrevistas semi-estruturadas, as quais foram aplicadas nas últimas duas semanas do curso. Foi elaborado um roteiro básico de entrevistas, reformulado conforme as exigências da situação. A partir desse procedimento, foi possível classificar tais formulações como informais.

Mann (1975) salienta que as entrevistas informais são aquelas em que o entrevistador enuncia o tema de seu interesse e, tendo começado a perguntar, permite ao informante impor a situação subseqüente. Acredita-se que com esse procedimento o pesquisador possa obter informações menos censuradas do que obteria se adotasse outros procedimentos.

Em relação ao enquadramento para a análise dos dados, a orientação foi a de captar o sistema de representações presentes e oriundos da vivência com jogos, valendo-se do quadro compreensivo como referência no tratamento dos dados, e ponto de partida para a montagem da estrutura analítica da investigação. A perspectiva do quadro compreensivo considera que a pesquisa científica pressupõe um processo de reflexão fundada na intuição através de um jogo de intersubjetividades que envolve a interação entre o cientista e o objeto de investigação. Assim, o objeto ganha objetividade somente quando observado e, portanto, é uma propriedade que se origina do observador.

Esse processo intersubjetivo não implica ser desnecessário um referencial que controle as próprias intenções do pesquisador. Pelo contrário, é imprescindível um modelo que norteie a interpretação dos dados. O quadro compreensivo, apesar de considerar a subjetividade do pesquisador como parte integrante da investigação, também é sujeito a uma racionalidade. O tratamento e a análise dos dados devem ser examinados e agrupados num referencial que lhes dê consistência interna.

\section{Construção conceitual da pesquisa}

A elaboração conceitual desta pesquisa foi calcada nas seguintes definições e enfoques:

a) reconhece que o aprendizado é um processo pelo qual o conhecimento é criado;

b) o conhecimento é constituído de aspectos cognitivos e valorativos;

c) o conhecimento se organiza em torno de um propósito, que é tanto objetivo quanto subjetivo;

d) o aprendizado pode ser abordado pelas seguintes dimensões: cognitiva, afetiva e psicomotora;

e) o aprendizado gerencial segue essas dimensões e é composto de três categorias: conhecimentos, habilidades e atitudes (descritas no quadro 2); 
f) o aprendizado gerencial pode ser subdividido nos níveis instrumental (single loop), intermediário (double loop) e avançado (deutero).

Quadro 2 - Categorias de aprendizado gerencial

\begin{tabular}{lll}
\hline Conhecimentos & Habilidades & Atitudes \\
\hline $\begin{array}{l}\text { Conceitos de estratégia } \\
\text { empresarial }\end{array}$ & Relacionamento interpessoal & Postura contributiva $x$ competitiva \\
\hline Conceitos de mercadologia & Capacidade de trabalhar em equipe & $\begin{array}{l}\text { Postura individual } x \text { Postura } \\
\text { coletiva }\end{array}$ \\
\hline Conceitos de finanças & $\begin{array}{l}\text { Capacidade de processar } \\
\text { informações }\end{array}$ & Enfoque nos objetivos e resultados \\
\hline Conceitos de contabilidade & Raciocínio lógico & Postura de questionamento \\
\hline Conceitos de recursos humanos & Raciocínio matemático & $\begin{array}{l}\text { Flexibilidade e predisposição à } \\
\text { mudança }\end{array}$ \\
\hline Conceitos de logística e produção & Capacidade de negociação & Enfoque na simplicidade \\
\hline
\end{tabular}

Fonte: baseado em Sauaia (2000).

A partir desses conceitos, foi estipulado um plano analítico, estabelecendo-se três parâmetros para análise:

a) modelo pessoal: características pessoais e da história de vida dos participantes;

b) ambiente da simulação: diz respeito à condução e à estrutura do programa de simulação, bem como das interações estabelecidas pelos grupos durante a vivência;

c) resultado da simulação: refere-se aos conhecimentos, habilidades, atitudes e imagens da gestão influenciada pela vivência dos jogos.

A figura 1 exemplifica o modelo de análise seguido.

\section{Figura 1 - Modelo de análise}

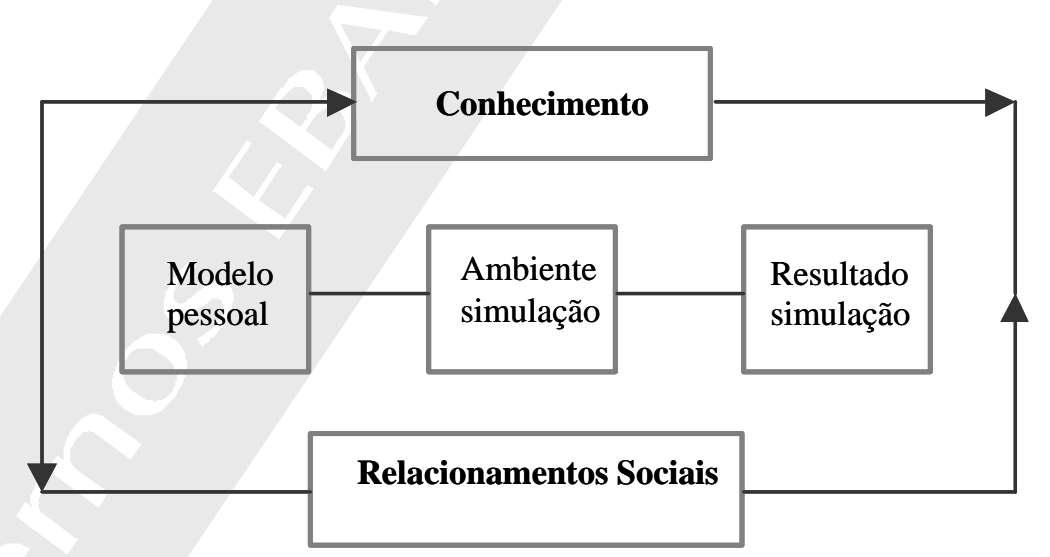

Fonte: elaborado pelos autores para a pesquisa.

\section{Descrição e análise dos dados}

A confrontação dos dados mostrou que os entrevistados apresentavam diferentes percepções no tocante aos conteúdos aprendidos. Porém, quando agrupados por formação profissional, verificou-se um padrão. As pessoas graduadas em administração (ou que cursaram pós-graduação nas áreas de administração geral, finanças ou produção) demonstraram convergência de opiniões quando comparadas com outras formações. Isso 
apontou para a evidência de que o nível de aprendizado propiciado pelos jogos está relacionado com o background ou a formação escolar dos indivíduos. Em consequiência, para fins da análise, segmentou-se os dados em duas categorias distintas:

a) categoria 1 - formação profissional em administração: englobando as pessoas com graduação em administração e/ou pós-graduação em finanças, produção ou administração geral; e

b) categoria 2 - formação em outras áreas: englobando indivíduos com graduação em outras profissões e/ou pós-graduação em outras áreas funcionais da administração.

Levando em consideração a primeira categoria, houve um entendimento geral de que somente a participação nos jogos de empresas não possibilitou a esses indivíduos aprender novos conceitos em gestão de negócios. Os entrevistados afirmaram que já tinham conhecimentos suficientes para atuação nos jogos, e de que, no caso de alguma dúvida, sabiam as fontes bibliográficas a serem acessadas. Desse modo, afirmaram que os jogos de empresas não lhes foram úteis na aquisição de novos conceitos.

Já os entrevistados com formação em outras áreas reconhecem o aprendizado conceitual como um dos resultados de sua participação nos jogos. Todavia, não conseguiram expressá-los objetivamente através de definições que revelassem o conteúdo assimilado. Na realidade, o que parece ter sido desencadeado foi um processo de familiarização com as representações, pensamentos e/ou idéias norteadoras do gerenciamento de um negócio. Nesse sentido, a formação de um quadro de referências próprias à administração ainda se encontra numa fase embrionária, não se apresentando como conteúdo consolidado e plenamente introjetado pelos indivíduos.

O fato é que os entrevistados, em ambas categorias, reconhecem unanimemente que os jogos, como metodologia isolada, não são adequados à aquisição de novos conceitos. Para isso, deveriam ser conjugados com a teoria, em momentos concomitantes, e inter-relacionados. Desse modo, conceitos como o de contabilidade, logística e produção e de finanças, dentre outros, seriam mais facilmente absorvidos. A dinâmica do jogo aliado a outras metodologias de caráter mais expositivo, propiciariam ao aluno um quadro mais consistente das atividades de administrador.

Assim, quando indagados sobre a pertinência dos jogos na utilização para altos executivos, todos os entrevistados, sem distinção, foram enfáticos em rechaçá-lo como recurso para o aprendizado conceitual, mas destacaram sua potencialidade como metodologia que aborda deficiências comportamentais e de atitudes, bem como sua capacidade de desenvolver uma visão mais abrangente e integradora do mundo dos negócios. Também sugeriram que o jogo de empresa pode fazer com que conhecimentos tácitos da gerência ou dos executivos venham a se tornar mais conscientes, uma vez que revela os pressupostos subjacentes de cada decisão. Como um entrevistado confessou:
[...] Para um executivo que anseia por uma posição de executivo na direção geral e ainda não teve essa chance, o jogo pode completar a visão dele. Em geral, os executivos começam a carreira em uma área funcional; então, tem executivos de marketing, operações. Então, eu acho que participar de um jogo como esse é muito útil para a gerência média e diretores de funções terem uma visão de um todo e verem como as decisões de operações afetam as decisões de marketing e vice-versa. Isso seria muito útil. Agora, para um executivo que já atua na direção também seria útil, mas de uma outra maneira: ele vê o conhecimento subjetivo dele muitas vezes, mais formalizado; ele seria obrigado a olhar os indicadores econômico-financeiros ou fazer a avaliação deles. Por que eu acho que em uma empresa a maneira como isso se dá não é tão formal quanto é em um jogo.

A análise das entrevistas revela que o jogo de empresas é bastante útil para integrar conhecimentos prévios, além de chamar a atenção para as relações de causalidade presentes nas decisões de gestão. Através dos jogos, os participantes têm a oportunidade de verificar o impacto de suas decisões e as conseqüências sobre os eventos futuros, incitando-os a uma reflexão sobre seus próprios atos e esquemas mentais. Passa a ser um movimento quase que espontâneo, o estabelecimento das relações de causa e efeito, onde se desencadeia uma atitude de inquirição sobre as razões dos resultados obtidos: 
[...] Por exemplo, quando você toma decisões você pode ser mais ou menos... não vou dizer racional, mas razoável; quando você observa o resultado, automaticamente, você vai buscar saber o que você errou, o que você deixou de acertar, o quanto de programa a mais você deveria ter investido, o quanto a menos você poderia ter produzido.[...] Eu acho que o tempo todo, eu estou vendo a decisão que vou tomar e como ela pode impactar outras. Agora, essas relações de causa e efeito tem efeito de feedback; então, não é uma coisa linear, uma causa tem um efeito lá. Existem alimentações positivas e negativas que você tem de levar em conta.

Os entrevistados, em geral, acreditam que os jogos estimulam uma reflexão mais sistematizada e profunda tanto em relação às suas próprias atitudes quanto no que se refere ao trabalho de equipe, mesmo considerando que os jogos não lhes possibilitaram adquirir novos conceitos sobre gestão. O jogo propiciou-lhes o movimento de auto-reflexão a partir do momento em que colocou o participante frente a frente com seus erros e acertos. Não há como se esquivar dos resultados obtidos ou da equipe da qual se faz parte. O jogo mostrou ser reflexo dos comportamentos e atitudes introjetadas, da dinâmica dos relacionamentos em operação a cada decisão e do movimento dos conceitos subjacentes a esses comportamentos. Os entrevistados, em ambas as categorias ("formação profissional em administração" e "outras formações"), reconhecem que seu principal aprendizado está no nível das atitudes e comportamentos, encarando os jogos como uma oportunidade de autoconhecimento:

[...] Conceitos, não, mas de atitudes que você aprende. Ah! foi o aprendizado da decisão de como tomar decisão de grupo. Aprendi, assim, a ouvir o que a outra pessoa quer falar e também a expor o que eu acho, [pois], às vezes, eu tenho a tendência de não falar muito. E isso acaba deixando a outra pessoa fazer alguma coisa, e aí você vê que não era melhor ter feito desse jeito. Eu consegui me expor mais do que com outra metodologia [...] Eu aprendi trabalho em equipe. O jogo oferece uma oportunidade para se interagir com os outros. Sinceramente, eu até me surpreendi com o meu poder de interação.

O trabalho em equipe foi um dos itens bastante citados como fonte de aprendizado, ressaltando-se a importância de se ouvir o p? rceiro e de sua valorização como elemento de transferência ou ampliador do conhecimento. Nesse sentido, os companheiros de equipe figuram como um dos principais fatores facilitadores do aprendizado, pois retiram do instrutor ou do professor o papel de transmissor do conhecimento. Aliás, o próprio conhecimento passa a ser relativizado, e questionado, por não haver uma solução tida como ótima que conduza ao melhor resultado.

O jogo proporciona previsibilidade à tomada de decisões, possibilitando que tais decisões, ao serem melhor formuladas, sejam tomadas pelos participantes de forma mais consciente. Desloca o ponto de vista autocentrado para o entorno, fazendo com que os jogadores busquem estabelecer uma linha mestra a ser seguida. Desse modo, teria os requisitos necessários para incentivar os indivíduos ao trabalho criativo, ainda que, curiosamente isso não tenha ocorrido na prática. Pelo contrário, os individuos desencadearam movimentos reativos ao lidarem com a concorrência, prospectaram suas decisões presos ao passado, analisando as próprias ações e as dos outros num horizonte de curto prazo. "Eu acho que o jogo é um trabalho reativo. Eu me senti bastante reativo, tipo dado o que aconteceu, o que a gente vai fazer em seguida. Eu não percebi em nenhum momento eu tentando fazer alguma coisa diferente."

Tal fato parece estar relacionado com as limitações da própria estrutura dos jogos, pois eles trabalham a partir de uma lógica matemática e quantificável, apresentando comportamento predeterminado das variáveis. Isso faz com que os indivíduos não se lancem a desafios inovadores, fixando-se nos resultados e na lógica interna do jogo que desenham os que serão considerados bem-sucedidos ou ganhadores.

Apesar do jogo ter sido considerado uma metodologia capaz de mobilizar o participante, envolvendo-o afetivamente em seu próprio aprendizado, esse envolvimento apresentou intensidades variadas no grupo estudado. As atitudes diante do processo de aprender parecem estar mais relacionadas com as motivações subjetivas e características de personalidade do que com o background escolar e de conhecimentos na área específica de Administração. 
Desse modo, as dimensões do aprendizado consideradas pelos participantes podem ser vistas de dois ângulos. Os indivíduos com conhecimentos prévios em Administração se envolveram mais com os jogos, desenvolvendo planilhas de cálculo que lhes possibilitassem prever os resultados de suas decisões. Os participantes com conhecimentos intuitivos em Administração demonstraram menor envolvimento, limitando suas atitudes a meros ensaios de tentativa e erro. Cabe a observação de que indivíduos sem conhecimentos técnicos específicos limitavam-se a dar opiniões tímidas, geralmente, solicitadas pelos parceiros de equipe que os chamavam a engajar-se mais efetivamente no jogo, demonstrando companheirismo e afabilidade.

Cabe ressaltar que os entrevistados, em ambas as categorias, não apontaram como aprendizado as habilidades gerenciais, tais como relacionamento interpessoal, capacidade de processar informações ou capacidade de negociação. Tal situação parece ter relação com inexistência de conflitos internos das equipes. Há claras indicações de que o jogo desenvolveu-se em clima ameno e amistoso, |prevalecendo a camaradagem e o companheirismo, dentro das equipes e entre elas.

Os participantes reconheceram que os jogos de empresa podem demonstrar fragilidades comportamentais. Entretanto, como não vivenciaram tal situação, ficaram com uma imagem positiva de seus pares. A postura contributiva prevaleceu internamente às equipes, e a competição entre elas se estabeleceu com enfoque nos objetivos que cada uma traçou. Também deve ser sublinhado, que no geral não reconhecem que a concepção de administração tenha mudado a partir da vivência nos jogos. Para eles, a administração é uma disciplina ou profissão multifacetada, permeada de incertezas, guiada menos por uma racionalidade objetiva e mais pelos aspectos substantivos e valorativos das ações e decisões. No entanto, são unânimes em considerar que nos jogos, os fatores que conduzem aos melhores resultados são, sem sombra de dúvidas, os conhecimentos técnicos, mais especificamente aqueles na área de finanças e orçamentária:

[ ] O que determina o resultado do jogo ? Eu acho, e cada vez me convenço mais disso, que é o conhecimento, ainda que o professor não concorde, e mais especificamente de finanças, $o$ conhecimento mínimo de administração de demanda elástica, essas coisas. E a dedicação para construir ferramentas de apoio, minimamente, uma planilha para simular resultados líquidos baseados nas decisões. Quem fez isso se deu bem.[ ] Quem pensa que pode ganhar um jogo sem o conhecimento de finanças, orçamento e essas coisas está totalmente enganado.

Portanto, conclui-se que não há como ganhar o jogo sem o embasamento teórico necessário, ainda que esse embasamento por si só não garanta a vitória. É vital a participação e o engajamento em cada decisão a ser tomada, além de uma acurada percepção de como o jogo funciona. Nesse sentido, apesar dos jogos tentarem simular a realidade, há o reconhecimento generalizado das diferenças substanciais entre ambiente real e simulado. O jogo permite que os participantes possam demonstrar suas emoções e manifestar opiniões, sem que se sintam constrangidos, diferentemente do cotidiano organizacional, quando precisam proteger suas identidades. A participação em uma simulação faz com que alguns dos participantes testem seus limites, ou mesmo possibilita-lhes ações mais ousadas que em situações reais nem sempre podem ser empreendidas. A formalidade cede lugar à espontaneidade, os desafios passam a ser compartilhados através do exercício dialogado. Assim, configura-se a competição; competição como algo que é antes de tudo, um processo de autoreflexão, projeção, prospecção e de imaginação das ações alheias. Esse movimento de auto-análise nem sempre encontra espaço de efetivação incentivado no ambiente real, que tende a levar os indivíduos a ações mecânicas ou de proteção de seu status quo. No entanto, esse processo de auto-indagação e de contemplação das atitudes e seus efeitos que o ambiente simulado permite, é com certeza condição sine qua non àquelas organizações que buscam desenvolver equipes com predisposição à aprendizagem.

Desse modo, o caso estudado leva à conclusão de que, se por um lado, o jogo de empresa como metodologia isolada não é suficiente para a formação conceitual imprescindível às identidades profissionais, por outro lado, é um recurso capaz de desencadear um processo de questionamento pessoal quanto aos pressupostos valorativos e técnicos presentes tanto no exercício das profissões como na constituição da identidade profissional de cada indivíduo. 


\section{Apreciação final}

Este artigo focalizou a aprendizagem desencadeada pela utilização de simulação empresarial. Os resultados revelaram que os jogos de empresa como metodologia isolada parecem surtir pouco efeito na aquisição de novos conceitos. Entretanto, permitem, para aqueles que já possuem conhecimentos prévios em gestão, a integração ou consolidação dos elementos teóricos que já foram incorporados ao repertório dos indivíduos e, até mesmo, a testagem desses conhecimentos. Nesse sentido, tornam explícitas as deficiências conceituais dos participantes, levando-os a questionar as suposições acerca da realidade empresarial presente em cada decisão simulada.

A maior potencialidade da metodologia de simulações está na capacidade de demonstrar relações de causalidade, e inter-relações conceituais, bem como a relação entre decisões e resultados. Portanto, as simulações empresariais parecem mais adequadas aos objetivos educacionais orientados a processos do que àqueles de caráter instrumental. Os jogos propiciam uma reflexão profunda em relação a si e aos outros, sugerindo ser recurso de aprendizagem adequado para possibilitar o auto-conhecimento.

O ambiente simulado contribui substancialmente para a habilidade coletiva de aprender, uma vez que os parceiros se apresentam como fonte de transferência de conhecimentos e como elementos facilitadores do aprendizado. No entanto, quando se trata de suscitar comportamentos criativos, parecem ser menos eficientes a esse propósito, devido a sua estrutura matematizável. Além disso, também não dão mostras significativas de induzir o desenvolvimento do pensamento de longo prazo, pois as jogadas são prospectadas pelos indivíduos em função dos erros passados. Assim, embora se projetem como metodologias que estimulam o questionamento e a auto-reflexão, parecem ser frágeis do ponto de vista de fomentar o pensamento prospectivo e/ou comportamentos proativos.

Cabe ser salientado que o background escolar dos indivíduos parece determinar a natureza do ciclo de aprendizado propiciado pelos jogos de empresa e de que a natureza das equipes relaciona-se à direção desse aprendizado. Equipes mais coesas e sem conflitos não permitem a visualização das deficiências comportamentais no trato com os pares ou com os competidores. Essa coesão não estimula o processo de autoreflexão no que diz respeito a buscar novas habilidades conceituais e comportamentais.

No tocante às dimensões de aprendizado ressalta-se que aqueles participantes com background em áreas quantitativas de gestão mostram-se mais envolvidos com os jogos. Já os participantes sem essa formação escolar limitam-se à observação de seus pares, tentando apreender seus conhecimentos. Assim, o envolvimento com o jogo conforma-se aos conhecimentos prévios em gestão. Todavia, independentemente desse envolvimento os jogos criam nos participantes, indistintamente, uma desordem "interior", uma ansiedade, conduzindo-os ao movimento de visualizar, criticar, e repensar suas ações.

Nesse sentido, os jogos de empresas permitem a integração do pensamento e da ação, conduzindo os indivíduos a remontarem seu quadro de referências pessoais a partir da vivência simulada. A metodologia dos jogos de empresas coloca-lhes a condição inexorável de se buscar as causas de cada comportamento ou resultado apresentado no jogo, em um nível em que a reflexão pode levar a mudanças dos pressupostos subjacentes em cada decisão. O jogo desempenha o papel de trazer para o nível consciente os modelos que estão em uso em cada ação, ajudando-os a reestruturar a visão de si mesmo, dos outros e das empresas.

Desse modo, permite que a aprendizagem individual seja compartilhada pelos outros participantes, podendo-se visualizar com clareza que o aprendizado é pautado em um sistema de troca coletivo. Dessa perspectiva, a utilização de jogos de empresas se ajusta ao nível intermediário de aprendizado gerencial, cujos objetivos sejam desenvolver novos esquemas interpretativos que guiem os processos decisórios das organizações.

O estudo demonstrou que a utilização dos jogos de empresas é pertinente a administradores com prévios conhecimentos conceituais em gestão, principalmente, aqueles de natureza quantitativa. Isso porque possibilita a integração desses conceitos, levando-os ao exame do pensamento sistêmico, bem como possibilita-lhes a consciência das causas de seus comportamentos gerenciais. Por outro lado, pessoas com conhecimentos rudimentares nas áreas quantitativas de gestão, embora percebam que a gestão ocorra de forma sistêmica, não 
são capazes de agirem no jogo com pensamento sistêmico devido às limitações conceituais. Cabe ressaltar que em ambos os grupos o jogo não foi capaz de nutrir uma nova concepção em relação aos negócios. Das categorias de aprendizado gerencial em que o jogo surtiu mais efeito sobressaiu a categoria "atitudes". Desse modo, apesar dos jogos apresentarem teoricamente a potencialidade de estimular comportamentos de aprendizagem (cujos pilares são a auto-reflexão), o pensamento sistêmico, o comportamento proativo e a capacidade de se antecipar a questões não respondidas, não foram capazes de cobrir todos esses aspectos. Tal resultado de pesquisa sugere que as simulações utilizadas isoladamente não permitem a integração das três categorias de aprendizado gerencial, tais como as categorias conhecimento, habilidades e atitudes, o que sugere a necessidade de conjugá-las com outras metodologias inter-relacionadas.

No entanto, não se pode deixar de mencionar as limitações dessas conclusões. Estudos que pretendem levantar a avaliação de metodologias utilizadas para fins específicos de educação ou desenvolvimento gerencial, se realizados com uma amostra mais variada em termos de características demográficas e de background profissional e escolar, podem oferecer uma visualização mais consistente quanto à avaliação dos métodos a serem utilizados em programas de educação. Além disso, deve ser ressaltado que essa avaliação se deu exclusivamente do ponto de vista daqueles que participaram da simulação, subsumindo da análise as variáveis que dizem respeito à condução do programa.

Pelo fato dessa amostra ser composta somente de estudantes de pós-graduação constitui uma limitação clara quanto a conclusões mais definitivas no tocante à potencialidade dos jogos para estimular identidades profissionais capazes de exercitar o auto-questionamento e o desenvolvimento do pensamento sistêmico. Portanto, sugere-se que pesquisas futuras, com outros tipos de público, apreciem com maior rigor em que medida as simulações são capazes de estimular comportamentos de aprendizagem organizacional. 


\section{Referências}

ALEE, V. The knowledge evolution. Expanding organizational intelligence. Washington: Butterworth-Heinemann,1997.

ANDERSON, P. H.; LAWTON, L. Simulation and learning: can we prove a relationship? Developments in Business Simulation and Experiential Leaming, v.24, 1997.

ARGYRIS, C., SCHÖN, D. Organizational learning. Reading, MA: Addison-Wesley,1978.

CHILD, J. Organizational learning in strategic alliances. In: CHILD, J.; FAULKNER, D. Cooperative strategy. London: Oxford University Press, 1997. cap.12

DEVITT, P. K. M easuring student learning using business simulations: a theory-based perspective. Developments in Business Simulation and Experiential Learning, v.24, 1997.

DI BELLA, A.; NEVIS, E. C. How organizations learn. An integrated strategy for building learning capability. San Francisco, CA.: Jossey Bass, 1998.

DOGSON. Organizational learning: a review of some literature. Organization Studies, v.3, n.14, 1993.

ELKJAER, Bente. Em busca de uma teoria de aprendizagem social. Prange, In: SM ITH, Mark Easterby et al. Aprendizagem organizacional e organização de aprendizagem: desenvolvimento na teoria e na prática. São Paulo: Atlas, 2001. Cap.5, p.100-116.

FARIA, A. J. The changing nature of simulation research: a brief ABSEL history. Developments in Business Simulation and Experiential Learning, v.27, 2000.

FRIEDMAN, V. J. The individual as agent of organizational learning. In: DIEKERS, M. et al. Handbook of Organizational Learning and Knowledge. Oxfo-d University Press, 2002. cap.17.

GARVIN, D. A. Building a learning organization. Harvard Business Review, v.71, n.4, p.78- 9, jul./ago.1993.

GOSEN J., WASHBUSH, J. Perceptions of learning in the simulations. Developments in Business Simulation and Experiential Learning, v.26, 1999.

KOLB, D. The learning styles inventory and learning styles inventory: technical manual. Boston: McBear, 1976.

MANN, P. HM étodos de investigação sociológica. Rio de Janeiro: Zahar, 1975

NONAKA, I.; TAKEUCHI, H. The knowledge creating company: how Japanese companies create the dynamics of innovation. New York: Oxford University Press, 1995.

PEACH, B., HORNYAK, M. What are simulations for? Learning objectives as a simulation device. Developments in Business Simulation and Experiential Learning, v.30, 2003.

SAUAIA, A. C. A. Satisfação e aprendizagem em jogos de empresas - contribuições para a educação gerencial. 272p. Tese de Doutorado em Administração - Universidade de São Paulo, 2000.

SCHUMANN, P. L. et al. A framework for evaluating simulations as educational tools. Developments in Business Simulation and Experiential Learning, v.28, 2001.

SENGE, Peter. A quinta disciplina: arte e prática da organização de aprendizagem. São Paulo: Best Seller, 1990.

SHRIVASTAVA, Paul. A typology of organization learning systems. Journal of Management Studies, Oxford, v.1, n.20, p.7-29, 1983.

SM ITH, M. E. Disciplines of organizational learning: contributions and critiques. Human Relations, New York, v.50, n.9, Sept. 1997.

WEIGERT, A. J., TEITGE, J. S. Society and identity. New York: Cambridge University Press, 1990. 